\title{
Neoadjuvant treatment of Dermatofibrosarcoma Protuberans of pancreas with Imatinib: case report and systematic review of literature
}

\author{
Mashaal Dhir ${ }^{1}$, David G Crockett ${ }^{2}$, Todd M Stevens ${ }^{3}$, Peter T Silberstein ${ }^{4}$, William J Hunter ${ }^{5}$ and Jason M Foster ${ }^{\text {** }}$
}

\begin{abstract}
Dermatofibrosarcoma Protuberans (DFSP) is a rare skin tumor, characterized by frequent local recurrence but is seldom metastatic. It is histologically characterized by storiform arrangement of spindle cells. Cytogenetically, most tumors are characterized by translocation 17:22 leading to overexpression of tyrosine kinase PDGFB which can be targeted with tyrosine kinase inhibitor, Imatinib. We describe the first case of unresectable pancreatic metastases from DFSP treated with neoadjuvant Imatinib and subsequently RO metastectomy. Additionally, a comprehensive systematic review of DFSP pancreatic metastases and the current published data on the use of Imatinib in DFSP is summarized.
\end{abstract}

Keywords: Pancreatic metastases, DFSP, Imatinib, Systematic review

\section{Background}

Dermatofibrosarcoma Protuberans (DFSP) is a rare fibrohistiocytic tumor of the skin or subcutaneous tissue that is often locally infiltrative but rarely metastatic [1,2]. Cytogenetically, DFSP is characterized by a pathognomonic translocation $\mathrm{t}(17 ; 22)(22 ; \mathrm{q} 13)$ with fusion of the COL1A1 gene on chromosome 17 with the PDGFB gene on chromosome 22 [3]. This event results in constitutive expression of ligand PDGFB creating an autocrine stimulatory loop that drives cell proliferation and fibrosis. Clinically, it commonly presents in younger adults growing slowly over many years $[2,4]$. Microsatellite instability and p53 mutations are involved in tumor progression to the fibrosarcomatous variant (DFSP-FS) [5]. Although the major recurrence risk for DFSP is local relapse, DFSP-FS subtype is associated with an aggressive clinical course, more likely to develop distant metastases [6,7]. Several case reports in the literature have demonstrated that DFSP can metastasize to the lungs [8-10], as well as, pancreatic or retroperitoneal spaces similar to the current case [11-13]. The optimal treatment of primary and metastatic DFSP is complete surgical resection with negative

\footnotetext{
* Correspondence: jfosterm@unmc.edu

'Department of Surgery, Surgical Oncology, 986345 University of Nebraska Medical Center, Omaha, NE 68198-6345, USA

Full list of author information is available at the end of the article
}

margins [14]. Over $90 \%$ of DFSPs, demonstrate a constitutive activation of platelet-derived growth factor receptor, making inhibition with a promiscuous tyrosine kinase inhibitor (TKI), Imatinib a good option for unresectable, recurrent, or metastatic disease [15]. There have been several reports of neoadjuvant Imatinib for locally advanced primary tumors and adjuvant Imatinib for resected margin positive primary disease and metastatic disease [16-20]. There have been no published reports of neoadjuvant Imatinib for unresectable metastatic DFSP to the pancreas successfully treated and subsequently resected. Here, we present the first reported case of unresectable metastatic DFSP to the pancreas, successfully resected following neoadjuvant Imatinib. Additionally, we conducted a systematic review of the literature for pancreatic metastases of DFSP and use of Imatinib in DFSP.

\section{Case presentation}

A 31 year old African American male was diagnosed with DFSP of the skin and soft tissue of the anterior left chest wall and shoulder in 2005 and underwent local excision at an outside facility in December, 2005. Grossly, the excised specimen consisted of a $22.0 \times 18.0 \times 9.5 \mathrm{~cm}$ portion of skin \& subcutaneous tissue that contained a multinodular and glistening dermal \& subcutaneous mass. 
Histologically, this revealed a neoplasm consisting of atypical spindled cells arranged in a storiform pattern that invaded the dermis and subcutaneous tissue (Figure 1A). Large parts of this tumor showed areas histologically reminiscent of fibrosarcoma (at least $75 \%$ of the tumor),
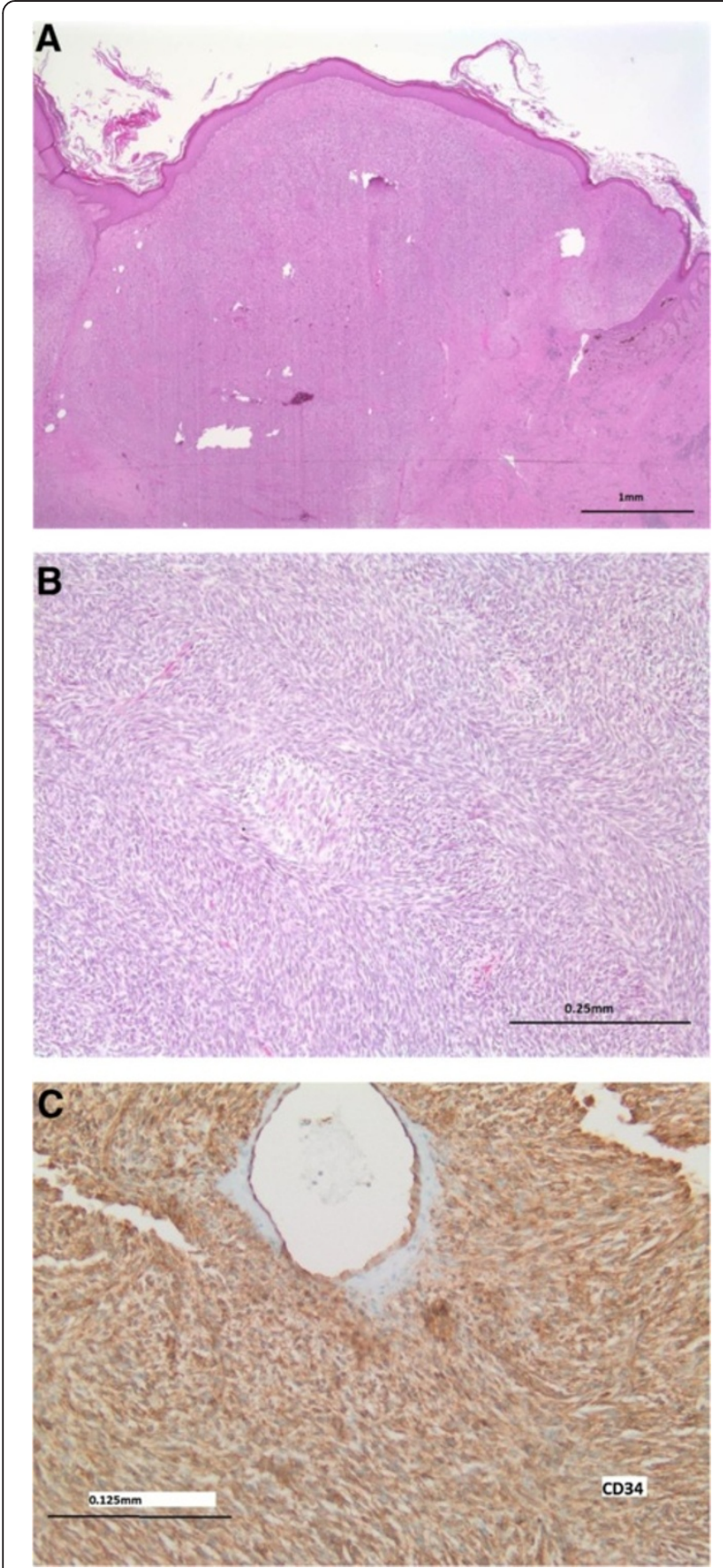

Figure 1 Histology of Primary tumor. A) The left chest wall mass excised in 2005 showed an invasive spindle cell neoplasm with B) areas of high grade, fibrosarcomatous transformation with Herringbone architecture. C) The tumor showed CD34 expression and this, along with the fibrosarcomatous areas and high mitotic rate, were consistent with a dermatofibrosarcoma protuberans with fibrosarcomatous transformation (DFSP-FS). characterized by spindled mesenchymal cells with high grade cytologic atypia arranged in broad fascicles forming a "Herringbone" pattern (Figure 1B), with more than 10 mitotic figures per high powered field. This neoplasm showed expression of CD34 by immunohistochemistry (Figure 1C), but was negative for Desmin, S100, Pan-cytokeratin, BCL-2, and CD117 expression. The deep margin of resection was focally positive for the neoplasm. A diagnosis of dermatofibrosarcoma protuberans with fibrosarcomatous transformation (DFSP-FS) was rendered.

The patient received no other therapy at that time and did well until October 2007, when he presented to the emergency department with severe anemia and a hemoglobin of $4 \mathrm{~g} / \mathrm{dL}$. Surgical Oncology was consulted after an abdominal CT scan revealed a heterogeneous mass in the left upper quadrant involving the pancreas, spleen, adrenal, left lobe of liver, and stomach measuring $17 \times 18 \times 23 \mathrm{~cm}$ (Figure 2A). A core biopsy of this retroperitoneal mass was obtained that showed spindle shaped mesenchymal cells with high grade cytologic atypia (Figure 2B) essentially identical to the fibrosarcomatous areas that were seen in the 2005 chest wall DFSP-FS. These malignant cells showed an identical immunophenotype as the original chest wall tumor (see above). A dual fusion DNA FISH probe set for the COL1A1 (17q21) and PDGFB (22q13) genes was positive for a COL1A1-PDGFB translocation (Figure $2 \mathrm{C}$ ), consistent with DFSP-FS metastasis to the retroperitoneum.

Radiographically, this retroperitoneal tumor was unresectable and the patient was started on Imatinib therapy $400 \mathrm{mg}$ BID. The patient tolerated this dose without any reported side effects and after 18 months of Imatinib therapy, the tumor exhibited a dramatic response with a $70 \%$ size reduction and radiographically appeared to be amenable to margin negative (R0) surgical resection (Figure 3). A left upper quadrant exenteration (en-bloc resection including a subtotal distal pancreatectomy, splenectomy, left adrenalectomy, and subtotal gastrectomy) was performed with negative margins on September 1, 2009 (Figure 4A-C). Post-Imatinib, this resected tumor showed dramatically altered histology, revealing primarily hyalinized and myxoid fibrous differentiated stroma (Figure 5A) with focal atypical spindle cells (Figure 5B-C) that revealed a COL1A1-PDGFB fusion by interphase FISH analysis, consistent with a dramatic gross and histologic response of the metastatic DFSP-FS to the Imatinib. The lymph nodes were negative for tumor.

The patient resumed adjuvant Imatinib for 6 months and remained free of disease for 14 months, off therapy. His imaging at 14 months revealed para-aortic nodal disease without evidence of local recurrence that responded to reinstitution of Imatinib at the same dose. The patient is now five years out from the initial 


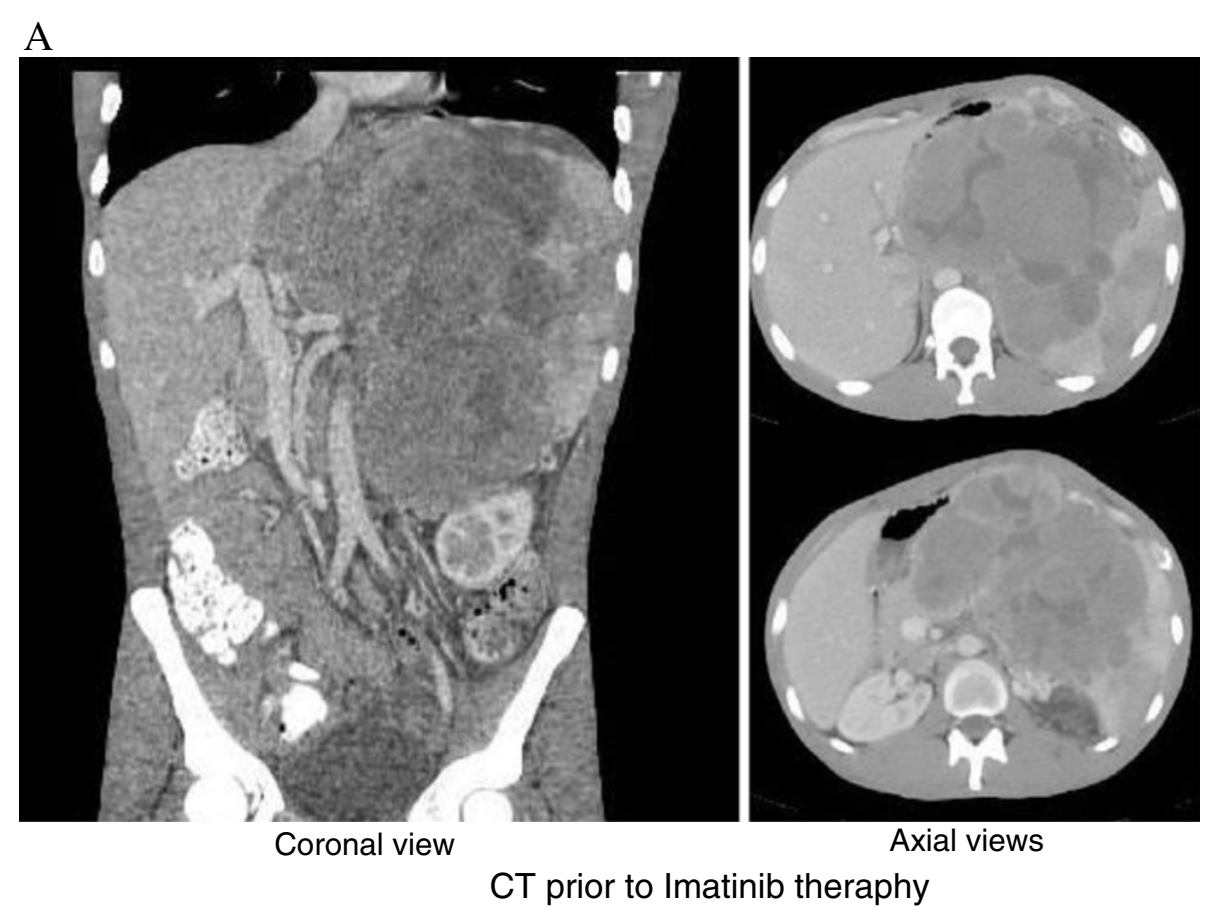

B

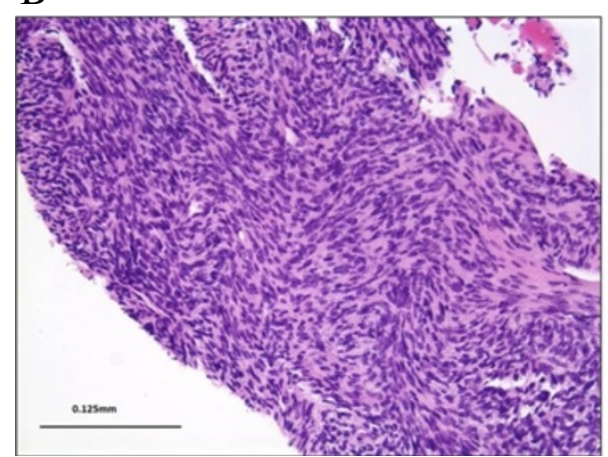

$\mathrm{C}$

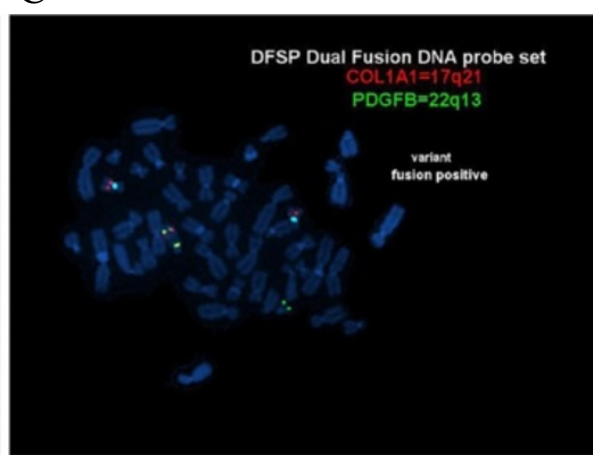

Figure 2 Radiographs of metastatic disease at diagnosis. A) CT scan demonstrating a large unresectable tumor involving all organs in the left upper abdomen. B) Biopsy of this mass showed malignant high grade spindled cells, C) a COL1A1-PDGFB translocation by dual fusion FISH probe set (yellow signals indicate the fusion signal), consistent with metastatic dermatofibrosarcoma protuberans with fibrosarcomatous transformation (DFSP-FS).

diagnosis of metastatic disease and remains in remission on Imatinib.

\section{Systematic review: Pancreatic metastasis of Dermatofibrosarcoma Protuberans Methodology}

A Medline search was performed using the key words (a) "Pancreatic metastasis" AND "Dermatofibrosarcoma Protuberans" (b) "Pancreas" AND "Dermatofibrosarcoma Protuberans". Similarly, an Embase search was performed using the key words (a) "Pancreatic metastasis" AND "Dermatofibrosarcoma Protuberans". Medline and Embase search using strategy (a) revealed 2 articles [13,21]. Search strategy (b) identified 3 articles [11,13,22]. Backward search was performed using the references from full texts of these 4 articles and no additional articles were found.

\section{Results}

We identified 4 articles reporting pancreatic metastases from DFSP [11,13,21,22]. A summary of these articles is provided in Additional file 1. Two of these patients were found to have pancreatic metastases during follow up and this appeared to be the only site of metastases [13,21]. In another patient reported by Winter et al., diagnosis was not clear preoperatively [11]. Interestingly, all three of these patients had aggressive disease with fibrosarcomatous variant of DFSP, high mitotic counts, relatively short 


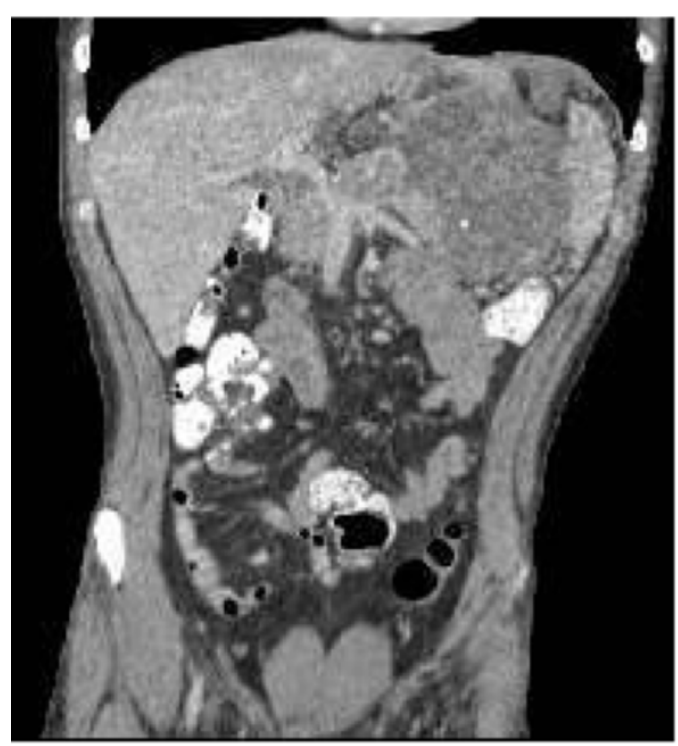

Coronal view

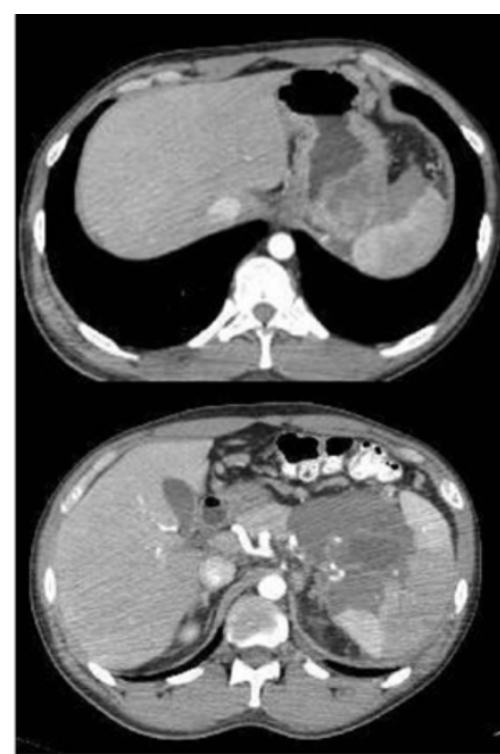

Axial views

\section{CT following Imatinib therapy}

Figure 3 CT scan illustrating post imatinib decrease in size of the tumor now amenable to surgical resection.

disease free interval and did not have local recurrence prior to development of metastatic disease. In the report by Onoda et al. a patient had multiple local recurrences with relatively more aggressive features at each recurrence and finally died of brain metastases. Patient was found to have pancreatic and other systemic metastases at autopsy. No studies described the use of Imatinib as a neoadjuvant strategy to treat the pancreatic metastases.

\section{Systematic review: use of Imatinib in Dermatofibrosarcoma Protuberans Methodology}

Figure 6 describes the search strategy in detail. A Medline search was performed using key words "Imatinib" AND "Dermatofibrosarcoma Protuberans" which resulted in 98 articles. A title and abstract review (wherever available) of all articles was performed. After exclusion of preclinical studies (studies on cell lines) we were able to identify 48 articles which mentioned DFSP and either implied or reported the use of Imatinib in patients. Full texts of these 45 articles were reviewed. Information was gathered from abstracts only, for 3 studies in non-English languages. Backward search was also performed using the references of these 45 articles and full texts of 12 randomly selected review articles. Twelve studies were excluded (exclusion criteria mentioned in Figure 6). Briefly, exclusion criteria include a) studies which did not use Imatinib b) duplicate studies c) studies which discussed molecular characteristics only d) critiques of other case reports e) described patients whose primary diagnosis was not DFSP. A total of 36 articles were included in the systematic review [16,18-20,23-54]. Response to Imatinib was defined as complete clinical or pathologic response, partial response or stable disease.

After completing the Medline search, an Embase search was also performed using key words "Imatinib" AND "Dermatofibrosarcoma Protuberans" which revealed 348 items including 152 review articles. After exclusion of studies already identified using Medline search, we were able to identify an additional 5 case reports [55-59] and 6 case series [60-65] (5 in abstract form [60,61,63-65]). There was one more case report in non-English language, describing neoadjuvant Imatinib for DFSP of the face, for which no abstract was available [66].

\section{Results}

We identified 23 case reports [19,20,23-25,27,29-32,35,38, 39,41,42,50-52], [55-59], 15 case series [16,26,33,34,36, $37,45,47,53,60-65]$, 6 phase II studies $[18,40,46,48,49]$ and 4 pediatric studies $[28,43,44,54]$ where Imatinib was used for the treatment of patients with DFSP. These studies include a total of 199 patients. Additional files 2, 3,4 and 5 provide a summary of these studies including case reports (Additional file 2), case series (Additional file 3), phase II studies (Additional file 4) and pediatric reports/series (Additional file 5). A phase II study of malignancies associated with Imatinib sensitive tyrosine kinases, by Heinrich et al. was excluded. A subset of 

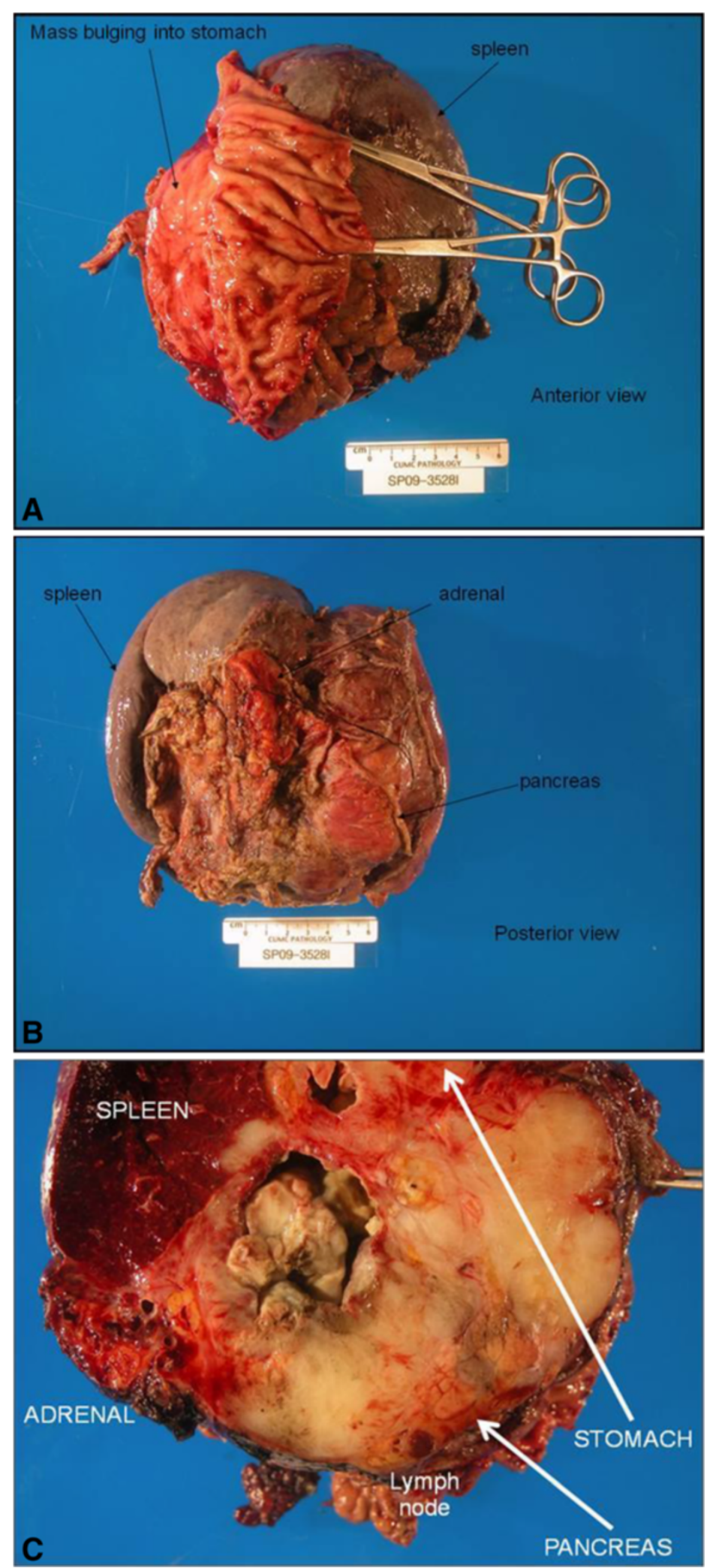

Figure 4 Gross $\mathrm{R}_{0}$ tumor resection specimen: subtotal distal pancreatectomy, subtotal gastrectomy, splenectomy, adrenalectomy. A) Anterior view B) Posterior view C) Cross sectional view. 

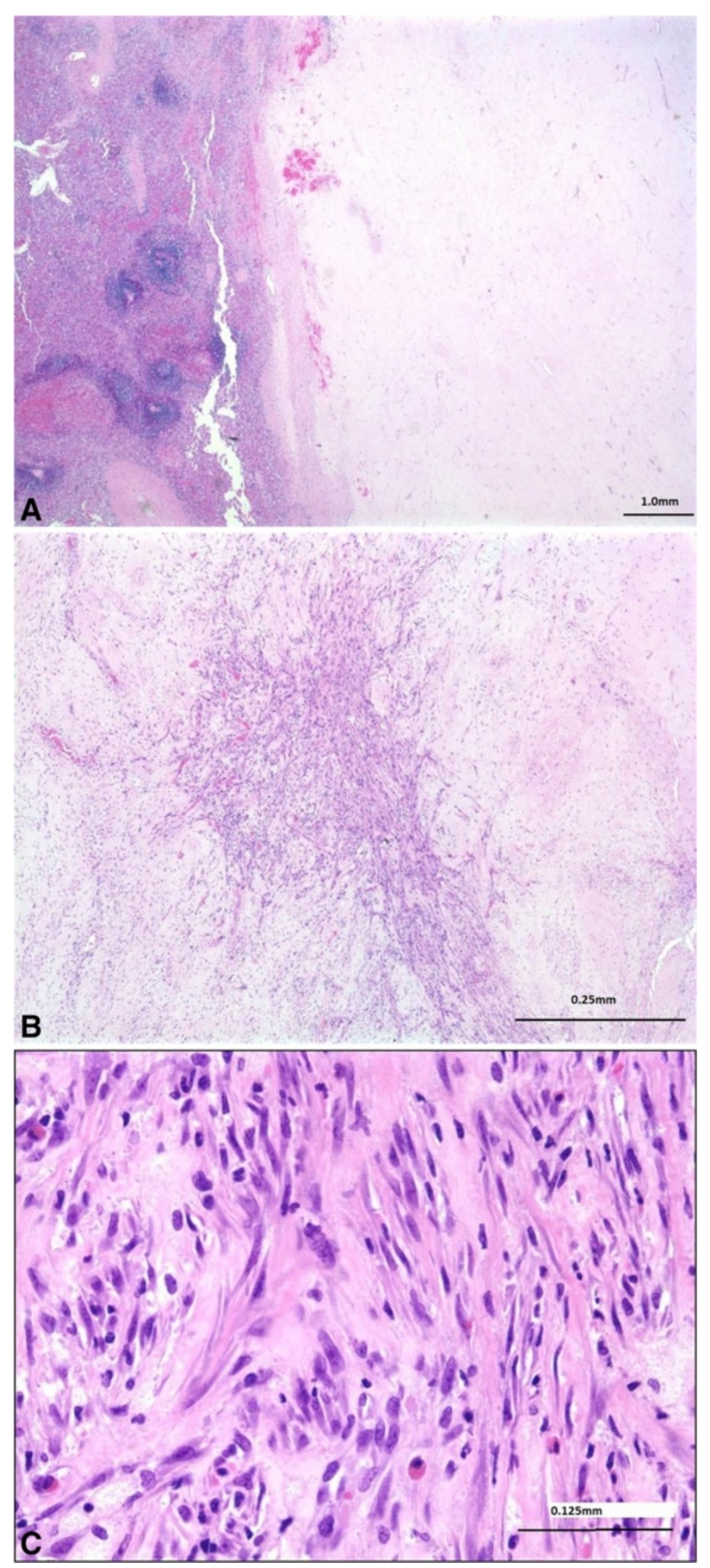

Figure 5 Histology post-Imatinib Resected retroperitoneal tumor showed a hyalinized hypocellular mass. A) Splenic tissue is demonstrated on the left in the current section. B \& C) Focally, the tumor demonstrated residual atypical spindle cells that revealed a COL1A1-PDGFB fusion by interphase FISH (not shown), consistent with a dramatic histologic response of metastatic DFSP-FS to Imatinib. 


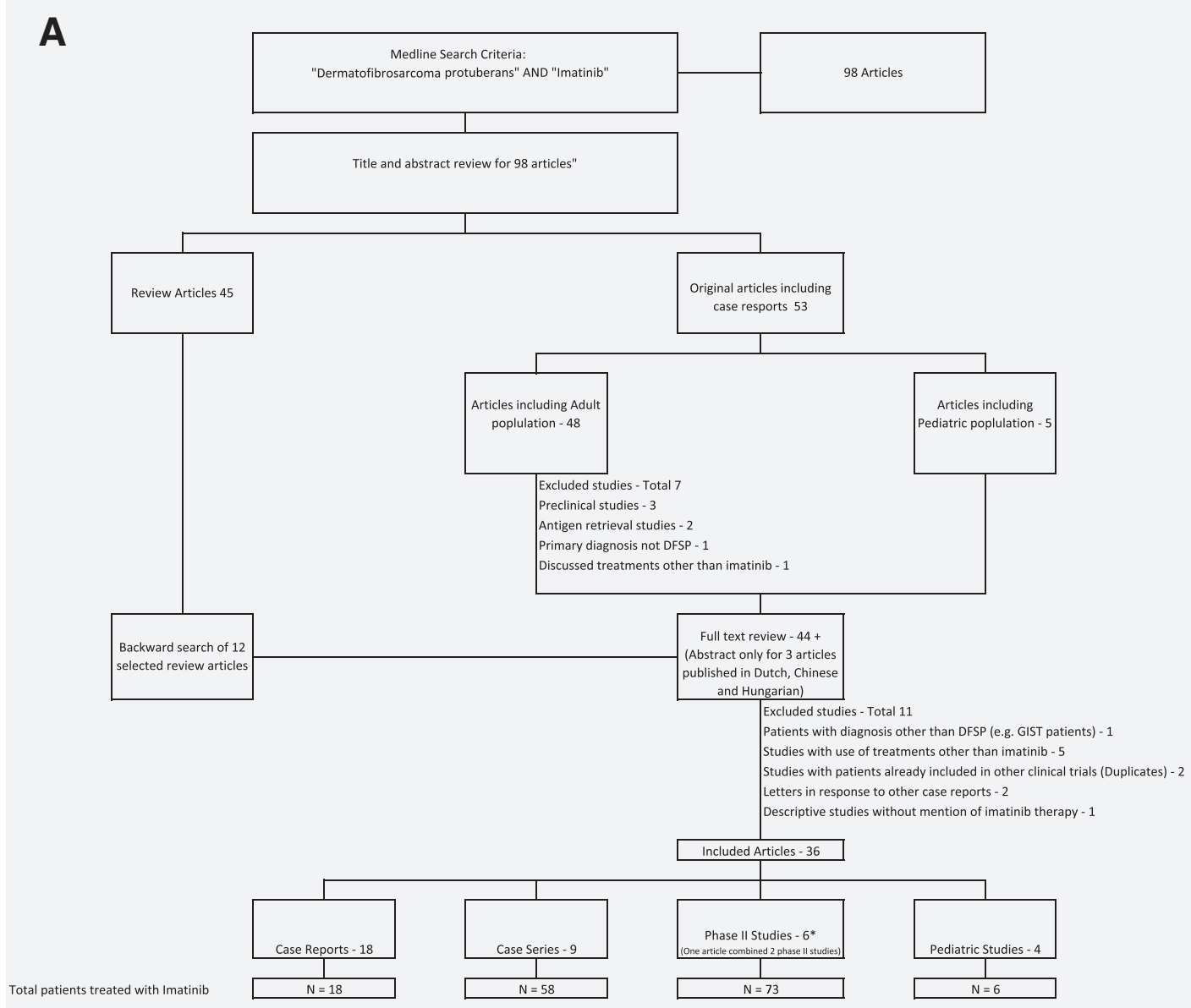

B

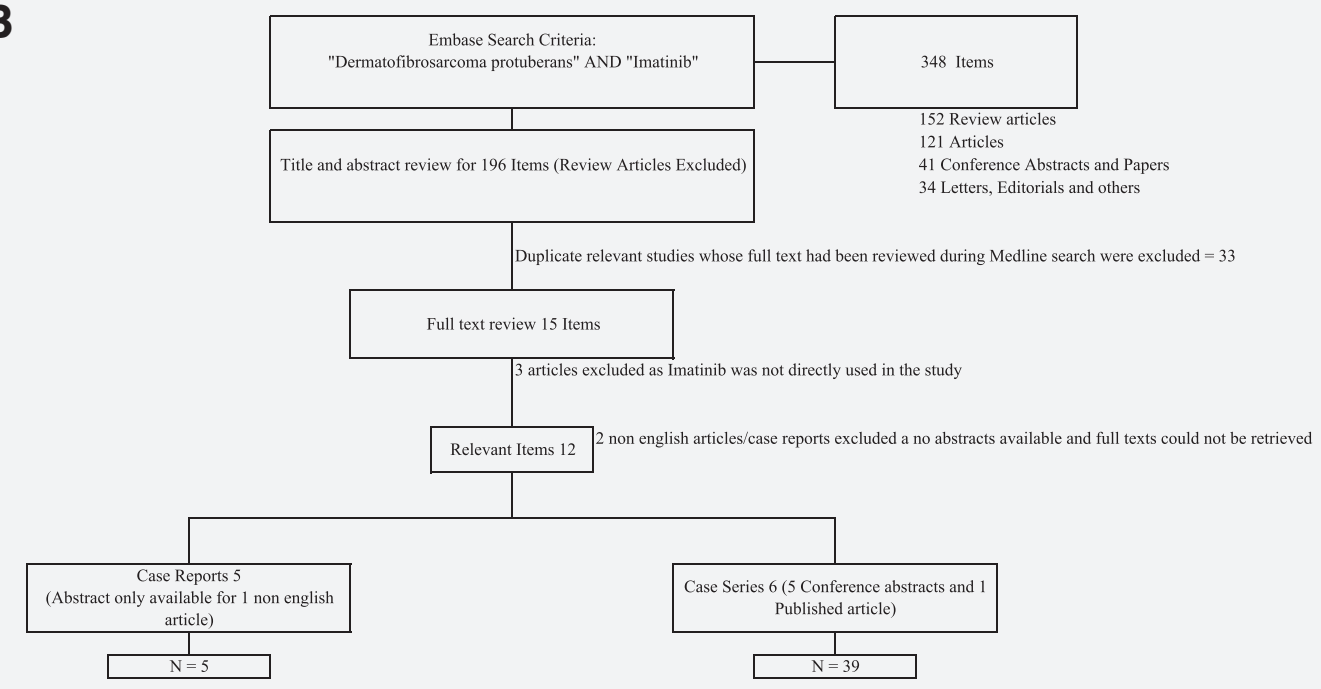

Figure 6 Search strategy flow diagrams. A \& B Diagrams depicting the search strategy for systematic review of the use of Imatinib in patients with Dermatofibrosarcoma Protuberans. 
patients with DFSP in this study were further analyzed and reported separately by McArthur et al. [40,67].

All except one case report described some response to Imatinib [38]. Since the response assessment criteria varied in many case series and to minimize bias, only phase II studies were used for calculation of percentage response to Imatinib. Overall combined response rate (Complete, partial or stable disease) was 65\% (48/74 patients) in phase II studies. Common indications for use of Imatinib in the selected studies included locally advanced primary, primary tumor in a cosmetically sensitive location, locally recurrent tumors, positive margins or metastatic disease. Commonly used dosages include $400 \mathrm{mg} /$ day, $400 \mathrm{mg}$ twice daily or $800 \mathrm{mg} /$ day. Some studies utilized a dose escalation strategy where patients were started on $400 \mathrm{mg} /$ day and dose was gradually increased to $600 \mathrm{mg} /$ day and then $800 \mathrm{mg} /$ day based on tolerance and side effects. Others utilized a higher dose of $400 \mathrm{mg}$ twice daily or $800 \mathrm{mg} /$ day and decreased the dose depending on the side effects. Duration of adjuvant strategy varied from 2 months to 2 years whereas neoadjuvant treatment was guided by response of the tumor to the therapy.

\section{Discussion}

To our knowledge, this is the first case report where an unresectable pancreatic metastasis was treated in a neoadjuvant fashion with Imatinib and an R0 resection was successfully performed. Consistent with findings observed in neoadjuvant therapy for primary cutaneous disease, when a clinical and radiographic reduction in tumor size is observed, it corresponds with the histologic findings of markedly decreased cellularity as evidenced by fewer CD34+ cells, along with significant hyalinization of dermal collagen as seen in our case (Figure 5A-C). In the current case, neoadjuvant Imatinib resolved the presenting symptoms (GI bleeding, anemia, and pain) and enabled R0 resection of an unresectable metastasis. The dose of $400 \mathrm{mg}$ BID was selected based on the only published phase II study, B2225 at that time in 2007 [40]. This study reported a $100 \%$ response rate in eight locally advanced $t(17 ; 22)$ positive DFPS tumors with four patients (50\%) exhibiting complete responses. Additionally McArthur et al. reported 7/8 (88\%) patients tolerated the therapy with only one patient requiring dose reduction to $600 \mathrm{mg}$. Since B2225 three additional phase II trials (Additional file 4) have been conducted evaluating $400 \mathrm{mg}, 600 \mathrm{mg}$ and $800 \mathrm{mg}$ doses which have reported similar efficacy and tolerance profiles $[46,49]$.

In this case $400 \mathrm{mg}$ BID Imatinib followed by resection facilitated excellent local control evident now 5 years post metastatectomy, 10-years from primary cutaneous diagnosis without resection bed recurrence. Although, the patient did develop distant, para-aortic nodal metastasis
14 months post-resection, metastatic disease remained Imatinib responsive and demonstrated radiographic resolution with therapy. Importantly the patient did not report any significant gastrointestinal or other side effects during neoadjuvant therapy or subsequent therapy for nodal recurrence.

\section{Conclusions}

In conclusion, given the intrinsic biological sensitivity of COL1A1/PDGFB positive DFSP to Imatinib, neoadjuvant therapy with this medication may not only be an important tool in managing locally advanced and recurrent cutaneous disease but equally valuable in unresectable or marginally resectable metastatic DFSP; facilitating margin negative resection, improving local control, and extending disease free and overall survival. The response observed following neoadjuvant Imatinib may also be useful as an in vivo test of tumor's responsiveness and may be useful in determine the best post-operative adjuvant therapy. Neoadjuvant and adjuvant Imatinib is well established in Gastrointestinal Stromal Tumors (GIST), unlike in DFSP. The results from the closed clinical trial NCT00243191/ SARC004 will provide insight into the value of short course therapy in cutaneous disease but additional trials are needed to address the value in the setting of metastatic DFSP. This report highlights the value of neoadjuvant Imatinib in facilitating surgical resection and the continued response of distant disease sites in a patient now over 5 -years with metastatic DFSP.

\section{Consent}

"Written informed consent was obtained from the patient for publication of this Case Report and any accompanying images. A copy of the written consent is available for review by the Editor-in-Chief of this journal."

\section{Additional files}

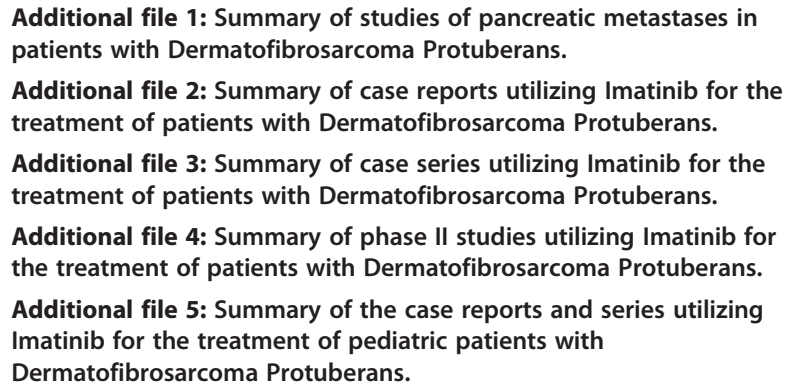

Additional file 1: Summary of studies of pancreatic metastases in patients with Dermatofibrosarcoma Protuberans.

Additional file 2: Summary of case reports utilizing Imatinib for the treatment of patients with Dermatofibrosarcoma Protuberans.

Additional file 3: Summary of case series utilizing Imatinib for the treatment of patients with Dermatofibrosarcoma Protuberans.

Additional file 4: Summary of phase II studies utilizing Imatinib for the treatment of patients with Dermatofibrosarcoma Protuberans.

Additional file 5: Summary of the case reports and series utilizing Imatinib for the treatment of pediatric patients with Dermatofibrosarcoma Protuberans.

\section{Abbreviations}

COLA1A1: Collagen 1 alpha 1; DFSP: Dermatofibrosarcoma protuberans; DFSP- FS: Dermatofibrosarcoma protuberans - fibrosarcomatous type; NED: No evidence of disease; PDGFB: Platelet derived growth factor beta.

\section{Competing interest}

The authors declare that they have no competing interest. 


\section{Authors' contributions}

MD - Conception and design, analysis and interpretation of the data, drafting and critical review of manuscript, final approval of the manuscript. DGC - conception, data acquisition, and final approval of manuscript. TMS \& WJH - conception, data acquisition, critical review and final approval of manuscript. PTS - data acquisition, critical review and final approval of manuscript JMF - Conception and design, analysis and interpretation of the data, drafting and critical review of manuscript, final approval of the manuscript.

\section{Author details}

'Department of Surgery, Surgical Oncology, 986345 University of Nebraska Medical Center, Omaha, NE 68198-6345, USA. ${ }^{2}$ Department of Hematology and Oncology, University of Nebraska Medical Center, Omaha, NE, USA. ${ }^{3}$ Department of Pathology, University of Missouri, Kansas City, MO, USA. ${ }^{4}$ Department of Hematology and Oncology, Creighton University Medical Center, Omaha, NE, USA. ${ }^{5}$ Department of Anatomic Pathology, Creighton University Medical Center, Omaha, NE, USA.

Received: 14 May 2014 Accepted: 7 July 2014

Published: 6 August 2014

\section{References}

1. Llombart B, Serra-Guillen C, Monteagudo C, Lopez Guerrero JA, Sanmartin O: Dermatofibrosarcoma protuberans: a comprehensive review and update on diagnosis and management. Semin Diagn Pathol 2013, 30:13-28.

2. Criscione VD, Weinstock MA: Descriptive epidemiology of dermatofibrosarcoma protuberans in the United States, 1973 to 2002. J Am Acad Dermatol 2007, 56:968-973.

3. McArthur GA: Dermatofibrosarcoma protuberans: a surgical disease with a molecular savior. Curr Opin Oncol 2006, 18:341-346.

4. Bowne WB, Antonescu CR, Leung DH, Katz SC, Hawkins WG, Woodruff JM, Brennan MF, Lewis JJ: Dermatofibrosarcoma protuberans: a clinicopathologic analysis of patients treated and followed at a single institution. Cancer 2000, 88:2711-2720.

5. Takahira T, Oda Y, Tamiya S, Yamamoto H, Kawaguchi K, Kobayashi C, Oda S, Iwamoto $Y$, Tsuneyoshi M: Microsatellite instability and p53 mutation associated with tumor progression in dermatofibrosarcoma protuberans. Hum Pathol 2004, 35:240-245.

6. Abbott JJ, Oliveira AM, Nascimento AG: The prognostic significance of fibrosarcomatous transformation in dermatofibrosarcoma protuberans. Am J Surg Pathol 2006, 30:436-443.

7. Mentzel T, Beham A, Katenkamp D, Dei Tos AP, Fletcher CD: Fibrosarcomatous ("high-grade") dermatofibrosarcoma protuberans: clinicopathologic and immunohistochemical study of a series of 41 cases with emphasis on prognostic significance. Am J Surg Pathol 1998, 22:576-587.

8. Kini H, Raghuveer CV, Pai MR, S K: Fibrosarcomatous Bednar tumor with distant metastases-a case report. Indian J Pathol Microbiol 2004, 47:26-29.

9. Westermann GW, Buerger H, Kappes U, Matzkies F, Kisters K Dermatofibrosarcoma protuberans with lung metastasis in a patient with progressive systemic sclerosis. South Med J 2002, 95:363-365.

10. Zorlu F, Yildiz F, Ertoy D, Atahan IL, Erden E: Dermatofibrosarcoma protuberans metastasizing to cavernous sinuses and lungs: a case report. Jpn J Clin Oncol 2001, 31:557-561.

11. Minter RM, Reith JD, Hochwald SN: Metastatic potential of dermatofibrosarcoma protuberans with fibrosarcomatous change. J Surg Oncol 2003, 82:201-208.

12. Suehara $Y$, Yazawa $Y$, Hitachi K: Metastatic Bednar tumor (pigmented dermatofibrosarcoma protuberans) with fibrosarcomatous change: a case report. J Orthop Sci 2004, 9:662-665.

13. Yokoyama Y, Murakami Y, Sasaki M, Morifuji M, Hayashidani Y, Kobayashi T, Sudo T, Sueda T: Pancreatic metastasis of dermatofibrosarcoma protuberans. J Gastroenterol 2004, 39:798-800

14. Meguerditchian AN, Wang J, Lema B, Kraybill WG, Zeitouni NC, Kane JM 3rd: Wide excision or Mohs micrographic surgery for the treatment of primary dermatofibrosarcoma protuberans. Am J Clin Oncol 2010, 33:300-303.

15. Lemm D, Mugge LO, Mentzel T, Hoffken K: Current treatment options in dermatofibrosarcoma protuberans. J Cancer Res Clin Oncol 2009, 135:653-665.
16. Han A, Chen EH, Niedt G, Sherman W, Ratner D: Neoadjuvant imatinib therapy for dermatofibrosarcoma protuberans. Arch Dermatol 2009, 145:792-796.

17. Johnson-Jahangir $H$, Sherman W, Ratner D: Using imatinib as neoadjuvant therapy in dermatofibrosarcoma protuberans: potential pluses and minuses. J Natl Compr Canc Netw 8:881-885.

18. Kerob D, Porcher R, Verola O, Dalle S, Maubec E, Aubin F, D'Incan M, Bodokh I, Boulinguez S, Madelaine-Chambrin I, Mathieu-Boue A, Servant JM, de Kerviler E, Janin A, Calvo F, Pedeutour F, Lebbe C: Imatinib mesylate as a preoperative therapy in dermatofibrosarcoma: results of a multicenter phase II study on 25 patients. Clin Cancer Res 2010, 16:3288-3295.

19. Lemm D, Muegge LO, Hoeffken K, Aklan T, Mentzel T, Thorwarth M, Schultze-Mosgau S: Remission with Imatinib mesylate treatment in a patient with initially unresectable dermatofibrosarcoma protuberans-a case report. Oral Maxillofac Surg 2008, 12:209-213.

20. Savoia P, Ortoncelli M, Quaglino P, Bernengo MG: Imatinib mesylate in the treatment of a large unresectable dermatofibrosarcoma protuberans: a case study. Dermatol Surg 2006, 32:1097-1102.

21. Murata $\mathrm{H}$ : Fibrosarcomatous variant of dermatofibrosarcoma protuberans with pancreatic metastasis. Int I Dermatol 2014, 53:e140-e142.

22. Onoda N: Pigmented dermatofibrosarcoma protuberans (BednÃ $j$ r tumor). An autopsy case with systemic metastasis. Acta Pathol Jpn 1990, 40:935-940.

23. Rubin BP, Schuetze SM, Eary JF, Norwood TH, Mirza S, Conrad EU, Bruckner JD: Molecular targeting of platelet-derived growth factor B by imatinib mesylate in a patient with metastatic dermatofibrosarcoma protuberans. J Clin Oncol 2002, 20:3586-3591.

24. Baars A, Pinedo HM: Good response to treatment with the selective tyrosine-kinase inhibitor imatinib in a patient with metastatic dermatofibrosarcoma protuberans. Ned Tijdschr Geneeskd 2003, 147:2072-2076.

25. Bigby SM, Oei P, Lambie NK, Symmans PJ: Dermatofibrosarcoma protuberans: report of a case with a variant ring chromosome and metastases following pregnancy. J Cutan Pathol 2006, 33:383-388.

26. Edelweiss M, Malpica A: Dermatofibrosarcoma protuberans of the vulva: a clinicopathologic and immunohistochemical study of 13 cases. Am J Surg Pathol 2010, 34:393-400.

27. Fava P, Stroppiana E, Savoia P, Bernengo MG: Halo nevi related to treatment with imatinib in a dermatofibrosarcoma protuberans patient. $J$ Eur Acad Dermatol Venereol 2010, 24:244-245.

28. Gooskens SL, Oranje AP, van Adrichem LN, de Waard-van Der Spek FB, den Hollander JC, van de Ven CP, van den Heuvel-Eibrink MM: Imatinib mesylate for children with dermatofibrosarcoma protuberans (DFSP). Pediatr Blood Cancer 2010, 55:369-373.

29. Hong JY, Liu X, Mao M, Li M, Choi DI, Kang SW, Lee J, La Choi Y: Genetic aberrations in imatinib-resistant dermatofibrosarcoma protuberans revealed by whole genome sequencing. PLoS One 2013, 8:e69752.

30. Jeon IK, Kim JH, Kim SE, Kim SC, Roh MR: Successful treatment of unresectable dermatofibrosarcoma protuberans on finger with imatinib mesylate and Mohs microsurgery. J Dermatol 2013, 40:288-289.

31. Kamar FG, Kairouz VF, Sabri AN: Dermatofibrosarcoma protuberans (DFSP) successfully treated with sorafenib: case report. Clin Sarcoma Res 2013, 3(1):5

32. Kasper B, Lossignol D, Gil T, Flamen P, De Saint Aubain N, Awada A: Imatinib mesylate in a patient with metastatic disease originating from a dermatofibrosarcoma protuberans of the scalp. Anticancer Drugs 2006, 17:1223-1225.

33. Kerob D, Pedeutour F, Leboeuf C, Verola O, de Kerviler E, Servant JM, Sarandi F, Bousquet G, Madelaine-Chambrin I, Pruvost C, Calvo F, Janin A, Lebbe $C$ : Value of cytogenetic analysis in the treatment of dermatofibrosarcoma protuberans. J Clin Oncol 2008, 26:1757-1759.

34. Kim M, Huh CH, Cho KH, Cho S: A study on the prognostic value of clinical and surgical features of dermatofibrosarcoma protuberans in Korean patients. J Eur Acad Dermatol Venereol 2012, 26:964-971.

35. Labropoulos SV, Fletcher JA, Oliveira AM, Papadopoulos S, Razis ED: Sustained complete remission of metastatic dermatofibrosarcoma protuberans with imatinib mesylate. Anticancer Drugs 2005, 16:461-466.

36. Llombart B, Sanmartin O, Lopez-Guerrero JA, Monteagudo C, Serra C, Requena C, Poveda A, Vistos JL, Almenar S, Llombart-Bosch A, Guillen C: Dermatofibrosarcoma protuberans: clinical, pathological, and genetic (COL1A1-PDGFB) study with therapeutic implications. Histopathology 2009, 54:860-872. 
37. Maki RG, Awan RA, Dixon RH, Jhanwar S, Antonescu CR: Differential sensitivity to imatinib of 2 patients with metastatic sarcoma arising from dermatofibrosarcoma protuberans. Int J Cancer 2002, 100:623-626.

38. Marakovic J, Vilendecic M, Marinovic T, Lambasa S, Grahovac G: Intracranial recurrence and distant metastasis of scalp dermatofibrosarcoma protuberans. J Neurooncol 2008, 88:305-308

39. Mattox AK, Mehta Al, Grossi PM, Cummings TJ, Adamson DC: Response of malignant scalp dermatofibrosarcoma to presurgical targeted growth factor inhibition. J Neurosurg 2010, 112:965-977.

40. McArthur GA, Demetri GD, van Oosterom A, Heinrich MC, Debiec-Rychter M, Corless CL, Nikolova Z, Dimitrijevic S, Fletcher JA: Molecular and clinical analysis of locally advanced dermatofibrosarcoma protuberans treated with imatinib: Imatinib Target Exploration Consortium Study B2225. J Clin Oncol 2005, 23:866-873.

41. Mehrany K, Swanson NA, Heinrich MC, Weenig RH, Lee KK, White CR Jr, Devere TS: Dermatofibrosarcoma protuberans: a partial response to imatinib therapy. Dermato/ Surg 2006, 32:456-459.

42. Mizutani K, Tamada Y, Hara K, Tsuzuki T, Saeki H, Tamaki K, Matsumoto Y Imatinib mesylate inhibits the growth of metastatic lung lesions in a patient with dermatofibrosarcoma protuberans. Br J Dermatol 2004, 151:235-237.

43. Posso-De Los Rios CJ, Lara-Corrales I, Ho N: Dermatofibrosarcoma protuberans in pediatric patients: a report of 17 cases. J Cutan Med Surg 2014, 18:1-6.

44. Price VE, Fletcher JA, Zielenska M, Cole W, Viero S, Manson DE, Stuart M, Pappo AS: Imatinib mesylate: an attractive alternative in young children with large, surgically challenging dermatofibrosarcoma protuberans. Pediatr Blood Cancer 2005, 44:511-515.

45. Rutkowski P, Debiec-Rychter M, Nowecki Z, Michej W, Symonides M, Ptaszynski K, Ruka W: Treatment of advanced dermatofibrosarcoma protuberans with imatinib mesylate with or without surgical resection. J Eur Acad Dermatol Venereol 2011, 25:264-270.

46. Rutkowski P, Van Glabbeke M, Rankin CJ, Ruka W, Rubin BP, Debiec-Rychter M, Lazar A, Gelderblom H, Sciot R, Lopez-Terrada D, Hohenberger P, van Oosterom AT, Schuetze SM, European Organisation for Research and Treatment of Cancer Soft Tissue/Bone Sarcoma Group, Southwest Oncology Group: Imatinib mesylate in advanced dermatofibrosarcoma protuberans: pooled analysis of two phase II clinical trials. J Clin Oncol 2010, 28:1772-1779.

47. Stacchiotti S, Pedeutour F, Negri T, Conca E, Marrari A, Palassini E, Collini P, Keslair F, Morosi C, Gronchi A, Pilotti S, Casali PG: Dermatofibrosarcoma protuberans-derived fibrosarcoma: clinical history, biological profile and sensitivity to imatinib. Int J Cancer 2011, 129:1761-1772.

48. Sugiura H, Fujiwara Y, Ando M, Kawai A, Ogose A, Ozaki T, Yokoyama R, Hiruma T, Ishii T, Morioka H, Mugishima H: Multicenter phase II trial assessing effectiveness of imatinib mesylate on relapsed or refractory KIT-positive or PDGFR-positive sarcoma. J Orthop Sci 15:654-660.

49. Ugurel S, Mentzel T, Utikal J, Helmbold P, Mohr P, Pfohler C, Schiller M Hauschild A, Hein R, Kampgen E, Kellner I, Leverkus M, Becker JC, Ströbel P, Schadendorf D: Neoadjuvant imatinib in advanced primary or locally recurrent dermatofibrosarcoma protuberans: a multicenter phase II DeCOG trial with long-term follow-up. Clin Cancer Res 2014, 20:499-510.

50. Wang C, Luo Z, Zheng B, Chen Y, Cao X, Wang J, Zhang R, Shi Y: Imatinib mesylate treatment for a Chinese patient with metastatic and recurrent dermatofibrosarcoma protuberans: is sustained partial remission possible? Eur J Cancer Prev 2012, 21:585-587.

51. Wicherts DA, van Coevorden F, Klomp HM, van Huizum MA, Kerst JM, Haas $\mathrm{RL}$, van Boven $\mathrm{HH}$, van der Hage JA: Complete resection of recurrent and initially unresectable dermatofibrosarcoma protuberans downsized by Imatinib. World J Surg Oncol 2013, 11:59.

52. Wright Tl, Petersen JE: Treatment of recurrent dermatofibrosarcoma protuberans with imatinib mesylate, followed by Mohs micrographic surgery. Dermatol Surg 2007, 33:741-744.

53. Zhu JH, Li QW, Xiao WH, Sun JZ, Wang RL, Lu JY: Advanced dermatofibrosarcoma protuberans treated with imatinib mesylate. Zhonghua Zhong Liu Za Zhi 2011, 33:470-472.

54. Suzuki D, Kobayashi R, Yasuda K, Yamamoto H, Morioka K, Mikawa M, Kobayashi K: Congenital dermatofibrosarcoma protuberans in a newborn infant with a massive back tumor: favorable effects of oral imatinib on the control of residual tumor growth. J Pediatr Hematol Oncol 2011, 33:e304-e306
55. Agbetiafa K: Partial remission of an unresectable dermatofibrosarcoma protuberans in a Togolese patient treated with imatinib. Nouvelles Dermatologiques 2012, 31:167-169.

56. Chawla B: Recurrent Bilateral Dermatofibrosarcoma Protuberans of Eyelids. Ophthal Plast Reconstr Surg 2011, 27:e167-e168.

57. George S: Dermatofibrosarcoma protuberans case report: when drug therapy can obviate the need for surgery. Community Oncol 2007, 4:462-463.

58. Kreze A: Metastasis of Dermatofibrosarcoma from the Abdominal Wall to the Thyroid Gland: case report. Case Rep Med 2012, 118:1-4

59. Vagholkar K, Gopinathan I, Nair S, Nachane S, Joglekar O, Vaishampayan A: Dermatofibrosarcoma protuberans: a deceptive neoplasm. Internet $J$ Oncol 2012, 8(2). http://ispub.com/IJO/8/2/14075.

60. Eberst L: Scientific Programme â€" Proffered Papers (1990). Eur J Cancer 1990, 49:S759-S892.

61. Elrafei TNN, Chrysofakis G, Simmons N, Reed L: Dermatofibrosarcoma protuberans-derived fibrosarcoma: response to escalated-dose imatinib mesylate (IM) and second-generation kinase inhibitor nilotinib. J Clin Oncol 2011, 29. suppl abstr e20529.

62. Fields RC: Dermatofibrosarcoma protuberans (DFSP): Predictors of Recurrence and the Use of Systemic Therapy. Ann Surg Oncol 2011, 18:328-336.

63. Michej W: Treatment of advanced dermatofibrosarcoma protuberans with imatinib mesylate with or without surgical resection. Virchows Arch 2012, 461:S228.

64. Neves R: Melanoma 2010 Congress. Pigment Cell Melanoma Res 2010, 23:874-1004.

65. Sanmartin O: Locally advanced dermatofibrosarcoma protuberans treated with imatinib followed by Mohs surgery: results of six cases of a single institution. J Am Acad Dermatol 2009, 62:AB107.

66. Aguayo Ortiz RA: Dermatofibrosarcoma protuberans facial e imatinib neoadyuvante. Piel 2010, 25:285-287

67. Heinrich MC, Joensuu H, Demetri GD, Corless CL, Apperley J, Fletcher JA, Soulieres D, Dirnhofer S, Harlow A, Town A, McKinley A, Supple SG, Seymour J, Di Scala L, van Oosterom A, Herrmann R, Nikolova Z, McArthur AG, Imatinib Target Exploration Consortium Study B2225: Phase II, openlabel study evaluating the activity of imatinib in treating life-threatening malignancies known to be associated with imatinib-sensitive tyrosine kinases. Clin Cancer Res 2008, 14:2717-2725.

doi:10.1186/2045-3329-4-8

Cite this article as: Dhir et al:: Neoadjuvant treatment of

Dermatofibrosarcoma Protuberans of pancreas with Imatinib: case report and systematic review of literature. Clinical Sarcoma Research $20144: 8$

\section{Submit your next manuscript to BioMed Central and take full advantage of:}

- Convenient online submission

- Thorough peer review

- No space constraints or color figure charges

- Immediate publication on acceptance

- Inclusion in PubMed, CAS, Scopus and Google Scholar

- Research which is freely available for redistribution 